\section{The Assessment of Environmental and Occupational Exposure to Hazardous Substances by Biomonitoring}

by PD Dr. rer. nat. Lygia T. Budnik, Univ.-Prof. Dr. med. Xaver Baur in volume $6 / 2009$

\section{Epidemiological Benefits}

It is generally accepted that industrial biomonitoring is a valuable tool as it helps to control workplace-related threshold limit values. It is also capable to determine a quantitative relationship between external and internal exposure and to support the diagnosis of diseases caused by acute effects of harmful substances. Biomonitoring may also be used in epidemiological studies to determine group differences between subjects with high and low exposure to improve the description of average pollutant concentrations from chronic exposure.

However, when assessing health risks of chronic diseases with long induction periods that arise from these exposures, the article is a bit short-spoken. Biomonitoring is less meaningful when studying these diseases, such as most types of cancer (1). Due to the short half-life of most of these agents, past exposures can hardly be estimated by biomonitoring procedures. In some cases risk estimation is only possible when complex mathematical models are applied.

Occupational epidemiologists use a variety of methods to evaluate these exposure scenarios, including historical ones, and the associated risks. Data sources, such as registry data, archive materials, expert evaluations and personal assessment by employees, as well as biological parameters or workplace measurements, may be for example combined in job exposure matrices which allow for automatic classification of historical exposures to evaluate health risks in epidemiological studies.

DOl: 10.3238/arztebl.2009.0507b multiple environmental or occupational exposures to heavy metals in the development of cancer, she concluded that the combined effects of different metals may be greater than the sum of their individual effects (3). Perhaps then the cumulative effects of different metals might also effect the development of disease, even when they are all within the normal ranges. In my opinion, these aspects of chronic and complex exposure to heavy metals and pollutants deserve more attention, as this could help to guarantee comprehensive protection of the population, particularly of children and of people who are already ill.

D0l: 10.3238/arztebl.2009.0507a

\section{REFERENCES \\ 1. Tsao DA, Yu HS, Cheng JT, Ho CK, Chang HR: The change of $\beta$-adrenergic system in lead-induced hypertension. Toxicol Appl Pharmacol 2000; 164(2): 127-33. \\ 2. Navas-Acien A, Guallar E, Silbergeld EK, Rothenberg SJ: Lead exposure and cardiovascular disease - a systematic review. Environ Health Perspect 2007; 115: 472-82. \\ 3. Madden EF: The role of combined metal interactions in metal carcino- genesis: a review. Rev Environ Health 2003; 18(2): 91-109. \\ 4. Budnik LT, Baur X: The assessment of environmental and occupational exposure to hazardous substances by biomonitoring. Dtsch Arztebl Int 2009; 106: 91-7.}

Peter Jennrich

Marienstr. 1, 97070 Würzburg, Germany

peter_jennrich@yahoo.de

\section{REFERENCES}

1. Ahrens W, Behrens T, Mester B, Schmeißer N: Epidemiologie in der Arbeitswelt. Bundesgesundheitsblatt Gesundheitsforschung Gesundheitsschutz 2008; 51: 255-65.

2. Budnik L T, Baur X: The assessment of environmental and occupational exposure to hazardous substances by biomonitoring. Dtsch Arztebl Int 2009; 106: 91-7.

\section{Dr. med. Thomas Behrens, MPH}

Dr. med. Birte Mester, MPH

Bremer Institut für Präventionsforschung

und Sozialmedizin

Universität Bremen

Linzer Str. 10

28359 Bremen, Germany

behrens@bips.uni-bremen.de

\section{In Reply:}

Extremely complex interactions may occur when subjects are exposed to multiple pollutants. There are many unsettled issues and unknowns here. It is not essential that individual pollutants (such as heavy metals) should exceed reference or limit values. Additive, superadditive or even antagonistic effects are possible here, although only initial studies have been performed. Detailed recent studies have shown that lead does indeed cause a variety of adverse effects besides its well known neuro-toxicity and hematotoxicity. Timely and sensitive biomonitoring 
can help in clarifying the etiology, or in confirming or excluding the etiological role of lead.

Exposure biomonitoring alone is generally not helpful in risk assessment or in determining the etiology of a disease when the exposure is long past. As our article describes, biochemical and biological effect monitoring (such as DNA- or protein-adduct formation or chromosomal aberrations [1, 2]) are capable of recording longterm effects and can lead to important new information about dose-effect relationships at the molecular level. These validated toxicological data may be combined with other procedures, such as occupational medical assessments, and analyzed by mathematical models to give more precise risk assessments.

What is important is that biomonitoring results of this kind should be interpreted in the context of clinical findings. Evaluation of carcinogenic effects must include the long periods of latency, individual susceptibility and cocarcinogenic aspects. The medical advisory committee on occupational diseases has recently recommended that the interaction between two occupational agent groups, namely polycyclic aromatic hydrocarbons and cocarcinogenic asbestos fibers, should be included in the list of occupational diseases (3).

Classical exposure monitoring can be used in long term studies, for example, to investigate persistent biological substances which are absorbed from the environment and accumulated in the body. The American Environmental Protection Agency and the WHO are currently performing large scale studies to investigate the background exposure of the population to these pollutants (4).

DOl: 10.3238/arztebl.2009.0508a

\section{REFERENCES}

1. Norppa H, Bonassi S, Hansteen IL et al.: Chromosomal aberrations and SCEs as biomarkers of cancer risk. Mutat Res 2006; 600: 37-45.

2. Sabbioni G, Jones CR, Sepai 0 et al.: Biomarkers of exposure, effect, and susceptibility in workers exposed to nitrotoluenes. Cancer Epidemiol Biomarkers Prev 2006; 15(3): 559-66.

3. Der Ärztliche Sachverständigenbeirat „Berufskrankheiten“ beim Bundesministerium für Arbeit und Soziales. Wissenschaftliche Begründung für die Berufskrankheit „Lungenkrebs durch das Zusammenwirken von Asbestfaserstaub und polyzyklischen aromatischen Kohlenwasserstoffen“. GMBI 2007; 23: 474ff.

4. Food Safety, Foodborne Diseases and Zoonoses Department World Health Organization. Fourth WHO-coordinated survey of human milk for persistent organic pollutants in cooperation with UNEP. http://www.who.int/foodsafety/chem/POPprotocol.pdf

5. Budnik LT, Baur X: The assessment of environmental and occupational exposure to hazardous substances by biomonitoring. Dtsch Arztebl Int 2009; 106: 91-7.

Univ.-Prof. Dr med. Xaver Baur PD Dr. rer. nat. Lygia T. Budnik Ordinariat für Arbeitsmedizin des Universitätsklinikums Hamburg-Eppendorf Zentralinstitut für Arbeitsmedizin und Maritime Medizin

Seewartenstr. 10

20459 Hamburg, Germany

Baur@uke.uni-hamburg.de

\section{Conflict of interest statement}

The authors of all contributions declare that no conflict of interest exists according

to the guidelines of the International Committee of Medical Journal Editors. 